\title{
Memorial de uma liderança indígena: a construção política da trajetória... driblando as armadilhas da colonização
}

Luana da Silva Cardoso ${ }^{1}$

DOI: http://dx.doi.org/10.20435/tellus.v19i39.634

Pertenço ao povo Kumaruara e venho de uma linhagem matriarcal, na qual as mulheres se constituem como o esteio da família. Nasci em Belém do Pará, no dia 16 de março de 1986. Minha mãe, Hélia Maria Gama da Silva, é nativa da aldeia de Solimões nas margens do rio Tapajós, Santarém, Pará. Aos 14 anos, minha mãe foi entregue a uma família de advogados de Belém (PA) para ser criada, devido à ocorrência de uma epidemia de tuberculose na aldeia, que chegou a dizimar muitas crianças. Quando ainda jovem, em Belém, conheceu meu pai, Walkyrio Mattos Cardoso, natural da Bahia. Não tenho conhecimento da história da família do meu pai, nem mesmo o nome da cidade em que ele nasceu. Minha mãe e meu pai tiveram três filhas: Elen da Silva Cardoso, a mais velha; eu sou a segunda filha; e Tainan da Silva Cardoso, a caçula.

Por volta de 1990, com a separação dos meus pais, minha mãe retornou com suas três filhas para seu lugar de origem, a aldeia Solimões. Meu pai parecia não estar de acordo que nós vivêssemos lá. Então, ele resolveu se mudar para a cidade de Santarém, comprou uma casinha simples de madeira e nos tirou da aldeia para morar com ele na cidade. Ele queria ficar mais próximo das filhas porque ele sabia que estava doente. Eu e minhas irmãs moramos com ele por aproximadamente um ano até ele vir a óbito. Minha mãe já tinha outro companheiro com quem teve também três filhos/as: Suelen da Silva Sousa, Hélida Maria da Silva Sousa e Wemerson da Silva Sousa.

A partir de então minha mãe passou ter nossa guarda, em meio a muitas dificuldades de nos manter na cidade. Vivíamos com um pé na cidade e outro na aldeia. Como na aldeia não tinha escola, permanecíamos mais tempo na cidade,

1 Universidade Federal do Pará (UFPA), Belém, Pará, Brasil. 
mas no período de férias escolares minha família e eu íamos para Solimões, com o intuito de visitar os parentes, minhas tias, minha avó, que lá residiam.

Vivíamos assim, "um pé lá outro cá", entre a aldeia e a cidade. Solimões, naquela época, era um aldeamento com poucas famílias. Todas tinham suas colônias onde faziam o plantio do roçado, onde desenvolviam a agricultura familiar. Eu tinha entre quatro e cinco anos de idade. Íamos para um lugarzinho no meio do mato, chamado Canta Galo, que ficava a uma hora de caminhada da aldeia de Solimões. Lugar batizado pela minha bisavó Sofia Gama, filha de uma Kumaruara e um português. Ela, conforme minha mãe conta, falava língua de índio, acredito que seja o nheengatu .

À noite sentávamos à frente da casa para ouvir as histórias de assombração contadas por nossos/as avós/as e tios/as. Sempre falaram muito em visagens e em pessoas que ficavam assombradas por terem sido judiada por bicho. Essas pessoas precisavam procurar um/a rezador/a para se curarem. Após a chegada do motor de energia, as rodas de contações de histórias deixaram de ser frequentes e isso teve consequências para sociabilidade das crianças, pois naquela época as rodas de contação de histórias eram o passatempo no período da noite. Eram contadas histórias da mulher de branco, chupa-chupa, curupira, jurupari, boto .

A partir dos dois anos de idade, comecei a ter contato e vivência junto com meus parentes na aldeia. Cultivávamos café, cana-de-açúcar, cacau. Tinha de tudo: abacateiro, tamarineiro, laranjeira, tucumãzeiro, açaízeiro, bacababeira, cupuaçuzeiro, araçázeiro, urucuzeiro, limoeiro, mangueira, limoeiro-galego, vinagrirae, pimenteira dentre outras frutíferas. Também, se cultivava ervas medicinais como: anador, melhoral, vicki, cumaruzinho, folha grossa, crajuri, manjericão, vindicá, "açaizinho", capim santo. E ainda existia um lindo jardim com flores.

No Canta Galo tudo plantávamos, tudo comíamos. No roçado, além de mandioca e macaxeira, havia uma diversidade de raízes: babata, batata-doce, cara roxo, cara espinho, maniquera. Como morávamos mais dentro do mato do que na beira do rio, comíamos mais alimentos derivados de raízes e caça: cutia, jacaré, veado, guariba, tatu, entre muitos outros.

Eram momentos em que aproveitávamos aquela liberdade para brincar muito durante o dia, ficando boa parte dele à beira do rio situado no terreno de 
Memorial de uma liderança indígena: a construção política da trajetória...

driblando as armadilhas da colonização

minha avó. Trabalhávamos na roça, fazíamos farinha, beiju, tapioca para garantirmos por um bom tempo nossa alimentação na cidade.

Minha infância lembra coisas como o sabor do leite de súcuba que tomávamos, o café (o café que nós mesmas plantávamos, colhíamos e moíamos) tirado do cafezal que meu avô plantou no caminho que descia para o igarapé. O café era torrado na vasilha de barro que minha bisavó fazia e socado no pilão, o gosto daquele café, nunca mais provei igual, ainda era adoçado com cana-de-açucar que minha bisavó também plantava próximo da casa.

\section{Da aldeia até a universidade}

Das idas e vindas da aldeia para cidade, trabalhei durante 7 anos da minha vida como babá, enquanto minha mãe trabalhava em cozinha de restaurante, de hotel e ainda executava trabalhos domésticos em diversas casas. Eu a acompanhava nas suas rotinas de trabalho e acabava cuidando dos filhos dos/as patrões/ as. E nos fins de semana íamos para feira vender "bugigangas", como minha mãe falava. Vendíamos objetos que meu tio, Raimundo José Gama, trazia de Belém e Manaus nas viagens que fazia como cozinheiro em embarcações de linha .

Aos 16 anos ganhei minha independência financeira ao começar a trabalhar por conta própria. Fui trabalhar como babá na casa de Nicolette Burford de Oliveira, uma inglesa que fazia a sua pesquisa de doutorado na região do Rio Arapiuns. Dentre muitas outras pessoas mais velhas que eu, fui escolhida para cuidar do pequeno Ravi, que na época tinha nove anos de idade. Depois de um tempo fui morar com eles e tivemos dois anos de convivência juntos. De uma relação de trabalho, com carteira assinada, construímos laços de respeito e amizade.

Como tinha que retornar para a Inglaterra, Nicolette me indicou para trabalhar com outra família. Era a família de Mark Harris, um antropólogo inglês que fazia pesquisa sobre a Guerra da Cabanagem, que ocorreu no período de 1835 a 1840 (HARRIS, 2010). Acompanhei o pesquisador e sua família em suas viagens de campo. Passamos quase trinta dias viajando pelo Baixo Amazonas, percorrendo lugares por onde passaram os cabanos, como eram conhecidos os protagonistas da Cabanagem. Em várias situações, Mark Harris me fazia muitas perguntas, na maioria das vezes relacionadas às minhas origens. Algumas eu tinha respostas outras não. Foi esta conjuntura que me despertou a curiosidade de saber o que era 
a Antropologia. No retorno da nossa viagem pelo Baixo Amazonas para Santarém, Mark Harris me apresentou para Florêncio Vaz, e disse o seguinte: "ele é indígena e antropólogo". Enchi-me de esperança em ser também uma antropóloga, mas não foi tão fácil como imaginei.

Depois da nossa expedição pelo Baixo Amazonas, recebi o convite de Mark e Anna, sua esposa, para viajar junto com sua família. Aceitei e passei seis meses na Escócia. Antes do meu retorno para o Brasil, ainda passei uns dias em Londres com Nicolete e Ravi. Uma experiência sem igual para quem nunca nem sequer tinha feito uma viagem de avião. Tudo era novidade: o jeito das pessoas, outra língua, outra comida, outro clima. Chorei, sofri muito de saudade da família, nunca tinha passado tanto tempo longe. A comunicação era difícil, raramente consegui fazer uma ligação telefônica. O jeito que mais me comunicava era por e-mail e cartão postal. Mas quando voltei tinha outra mentalidade, uma sede de estudar.

Ao retornar para o Brasil, completei 19 anos, procurei modos de ingressar no ensino superior. Deparei-me com dificuldades que já conhecia por acompanhar a luta da minha mãe para se formar em uma faculdade particular. Cheguei a ajudá-la pagar com as economias da minha viagem. Em Santarém, há duas universidades públicas: Universidade Estadual do Pará (UEPA) e Universidade Federal do Pará (UFPA). Porém a concorrência era muito grande, mas com a posterior criação da Universidade Federal do Oeste do Pará (UFOPA), em 2010, o acesso ao ensino superior cresceu e se popularizou, pois ofertam mais de 30 cursos, se ampliando para os municípios vizinhos. Há, também, faculdades particulares, mas eu não tinha condições financeiras para me manter num curso das particulares. Como eu tinha feito alguns cursos profissionalizantes (informática, assistente administrativo, recepção), comecei a trabalhar como secretária em escritórios, deixando de trabalhar como doméstica ou babá.

A partir de então, comecei estudar em cursinho pré-vestibular com o intuito de realizar as provas do Exame Nacional do Ensino Médio (ENEM) para concorrer a uma vaga em universidade em outras cidades, porque até então não havia curso de Ciências Sociais ou Antropologia em Santarém. Tentei, mas naquele e em outros momentos não consegui. Em 2011, foi criada a UFOPA e com isso foi ofertado o curso de Antropologia em Santarém. Em 2012, prestei o Processo Seletivo Especial Indígena e consegui realizar meu sonho de estudar Antropologia. 
Indígena, mulher, estudante de antropologia e liderança: os diversos papeis sociais no percurso acadêmico

Sou estudante indígena: entrei na UFOPA como Luana e saí Luana Kumaruara. Mãe de Yara Kumaruara da Silva Neves (4 anos) e Kauê Borari Kumaruara (2 anos). Fizemos questão de registrar os nomes dos meus filhos em cartório com referência à etnia.

Figura 1- Eu e meus filhos

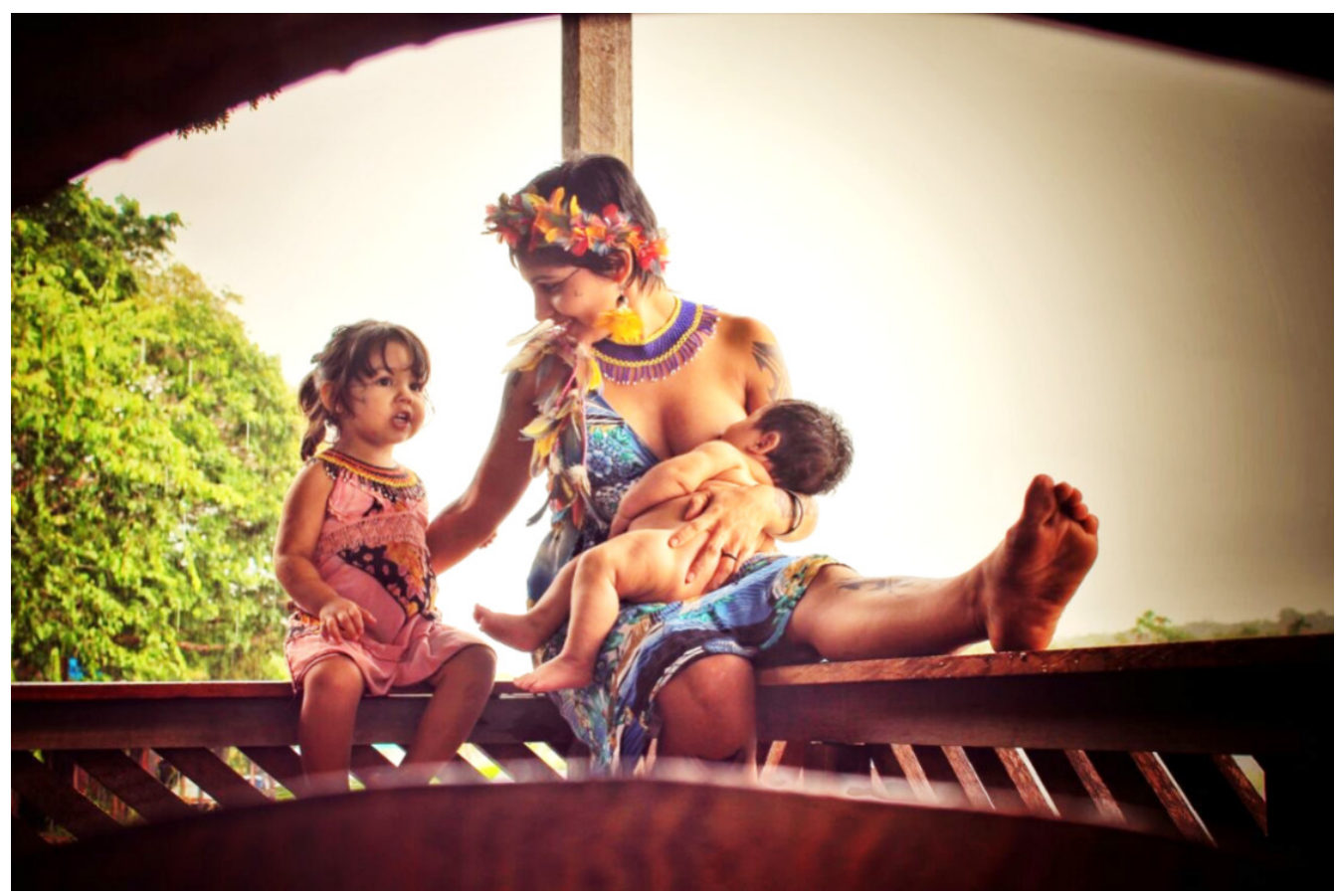

Foto: Vanessa Barros (2017).

No primeiro ano de curso conheci muitos/as parentes, passei a frequentar o turno da noite, pois ainda mantinha um vínculo empregatício. Era difícil estudar algumas disciplinas no período integral. Durante um ano não fui contemplada com bolsa estudantil. Passei um ano sem bolsa, com o desafio de conciliar os estudos, o trabalho, os afazeres domésticos e familiares.

Em meio a tantas dificuldades, fui começando a me integrar junto ao movimento indígena. Sempre falo que a "universidade me descobriu para o movimento 
indígena". Assim que ingressei na universidade percebi que há reserva de vagas para indígenas, mas não havia garantias de permanência desses estudantes na cidade. Eu não era única que não recebia bolsa. Além disso, o pagamento dos/ as bolsistas sempre atrasava. Assim, eu presenciava as dificuldades de muitos/as parentes, uns chegaram a morar comigo e outros/as desistiram. É muito triste ver os/as parentes desistindo de realizar o sonho de ter direito a estudar.

Em 2013, estudantes indígenas do Baixo Tapajós participaram do I Encontro Nacional de Estudantes Indígenas (ENEI), realizado na Universidade Federal de São Carlos (UFSCar). Ao retornarem, João Tapajós e Poró Borari, nos contaram sobre iniciativas de organização de parentes em outras universidades pelo país. Então, tivemos a ideia de criar o Diretório Acadêmico Indígena (DAIN). Depois que começamos nos organizar enquanto estudantes, saíamos pelas ruas protestando contra o descaso com os indígenas e reivindicando assistência da UFOPA. Foi quando comecei a "pegar gosto" pelo movimento indígena, a me espelhar em jovens lideranças que independentemente da idade lutavam com bravura e sabiam bem porque estavam ali. Dentre esses líderes destaco: Poró Borari, João Tapajós, Karo Munduruku e lannuzy Tapajós, até então única mulher indígena a frente das mobilizações estudantis.

Eu já possuía uma experiência anterior de militância no Movimento Tapajós Vivo (MTV). O Padre Edilberto Sena sempre me convidava para participar das formações de organizações de base. Fui batizada de "ovelha" dele, e ele de "meu pastor". E foi com base na experiência junto às Comunidades Eclesiais de Base (CEB's) e acompanhando a garra dos/as parentes que fui me lapidando enquanto liderança.

Em 2013, fiz o meu primeiro manifesto dentro da universidade durante o Seminário de discussão do Processo Seletivo Especial Indígena (PSEI), pelo qual adentrei na instituição. Na ocasião, apresentei uma carta de repúdio contra as violações dos direitos indígenas garantidos em programas do Ministério da Educação. Depois disso, as bolsas passaram a ser pagas no dia certo, o número de bolsas foi ampliando e eu passei a receber uma bolsa que me garantiu a possibilidade de estudar.

Desde então fui me destacando dentro do movimento indígena, sempre sendo convidada para espaços de debates e palestras. Em 2014, perante assembleia do Conselho Indígena Tapajós Arapiuns (CITA) , fui indicada para fazer parte da executiva como secretária. Assumi o posto de jovem liderança indígena e ao mesmo tempo o posto de mãe, pois estava grávida da minha filha, Yara. 
Depois que estive na coordenação do CITA, não parei mais. Após mandato de dois anos, passei a compor o conselho de lideranças do CITA como representante titular do Território Kumaruara. Em 2016, assumi posição de destaque na organização de mulheres indígenas do Baixo Tapajós para reativar o Departamento de Mulheres Indígenas do CITA. Em 2017, captamos recursos através de projeto para iniciar as mobilizações de base nos territórios. Também firmamos parceria para fortalecer a organização das mulheres indígenas do território Kumaruara por intermédio do Projeto Mãe D’Água - Mulheres Guerreiras Fortalecidas na Vigilância de seus Territórios e em Defesa de seus Direitos Humanos e Sócio Ambientais na Amazônia, executado pelo Fórum da Amazônia Oriental (FAOR) em parceria com CITA. Neste projeto tenho me dedicado ao projeto audiovisual junto as mulheres Kumaruara.

Figura 2- Eu, Luana Kumaruara, com minha filha Yara e Fabiana Borari em manifestação no centro de Santarém contra cortes no orçamento da saúde e educação (2016)

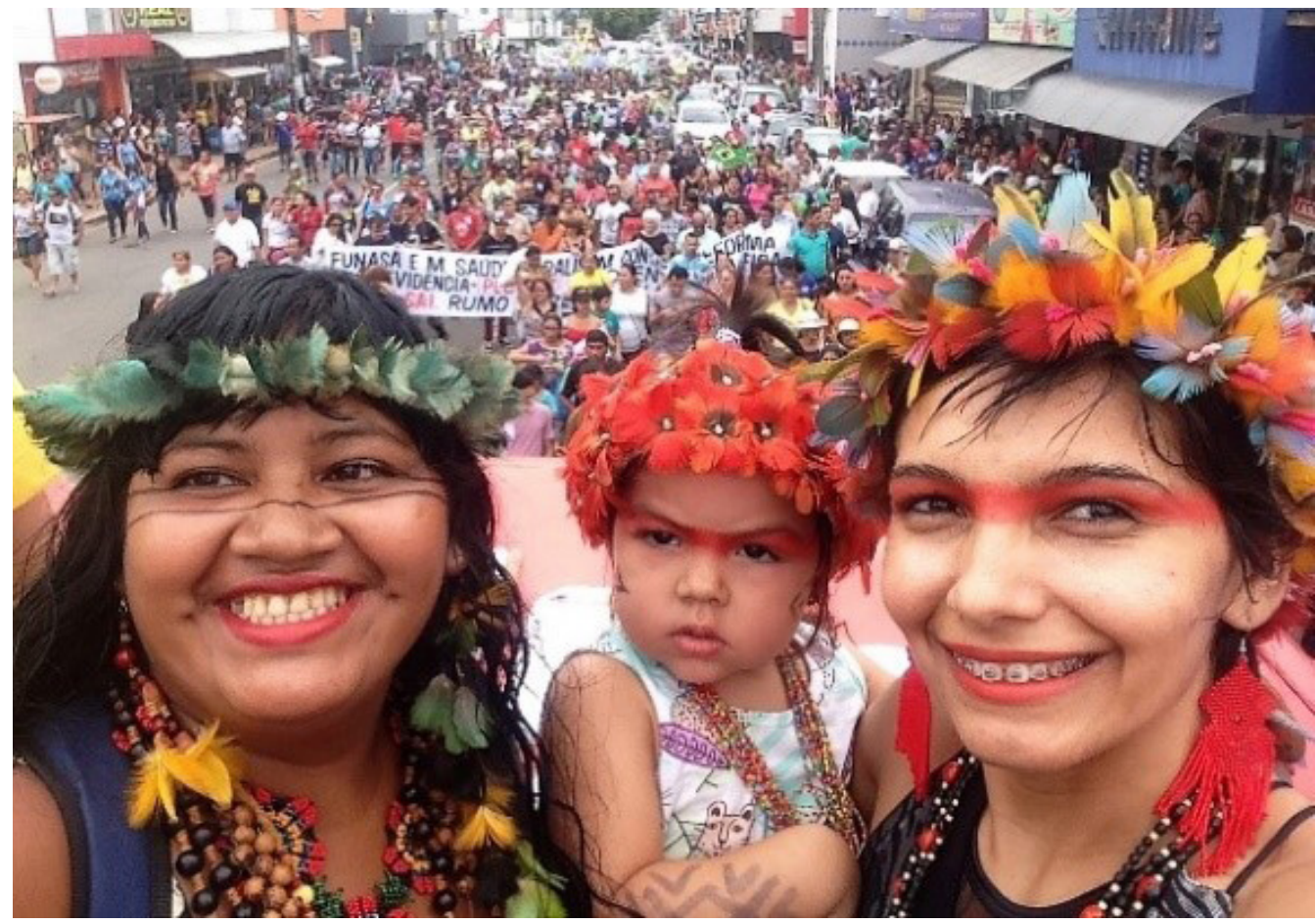

Foto: Acervo da autora. 
Figura 3- Eu no Acampamento Terra Livre (ATL) em Brasília (2016)

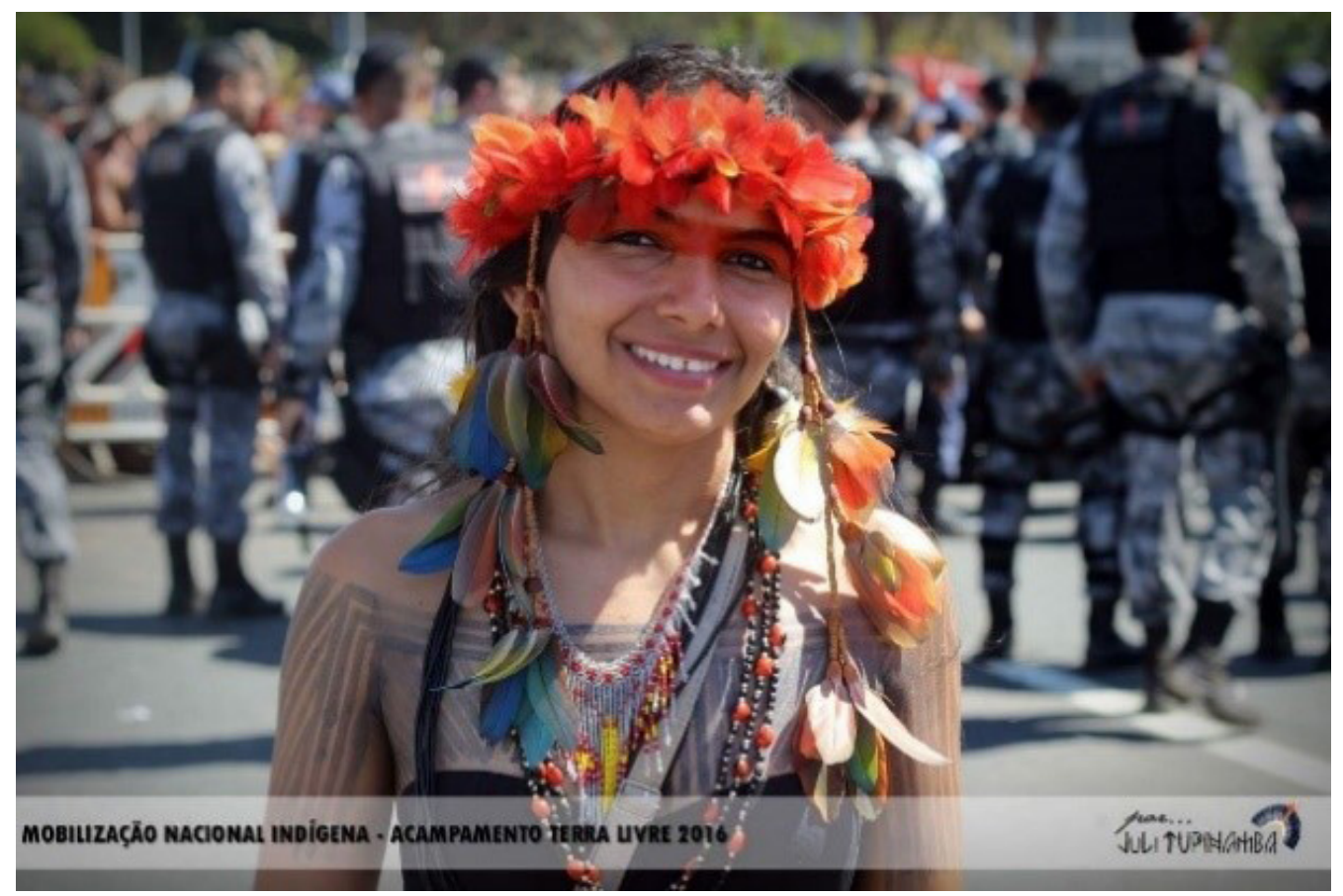

Foto: Juli Tupinambá (2016).

Além de atuar na elaboração e execução de projetos junto ao movimento indígena, desde o meu ingresso na UFOPA, sempre procurei participar de projetos de pesquisas, mesmo de forma voluntária. Durante quase dois anos, estive num projeto de extensão, sob orientação da professora Sandra Silva e do professor Itamar Paulino, chamado "Cultura Identidade e Memorial na Amazônia". O projeto era desenvolvido em quilombos do município de Óbidos.

Em 2015, tive a oportunidade de apresentar uma proposta para desenvolver um projeto de pesquisa direcionado à minha aldeia Solimões. Foi no âmbito do projeto de pesquisa "A Hora do Xibé", vinculado ao Programa de Extensão Patrimônio Cultural na Amazônia (PEPCA). O projeto "A Hora do Xibé" era coordenado pelo então meu orientador Florêncio Vaz. Foi nessa oportunidade que nos aproximamos. O primeiro plano de trabalho que submeti foi "O resgate cultural do cordão de pássaros do povo Kumaruara", e o segundo foi "O sabor e a arte do povo Kumaruara". 
Memorial de uma liderança indígena: a construção política da trajetória...

driblando as armadilhas da colonização

O projeto "A hora do Xibé" é um guarda-chuva para vários outros trabalhos a respeito da cultura amazônica. A proposta do projeto é difundir histórias, receitas, memórias, principalmente, pelo programa semanal mantido na Rádio Rural. A partir dos relatos registrados pela equipe do projeto "A hora do Xibé", tivemos o desafio de elaborar um livro com os depoimentos de curandeiros, pajés, benzedores, puxadores, parteiras (VAZ FILHO, 2016).

Essa experiência me despertou a vontade de conhecer mais de perto os trabalhos de cura dos Kumaruara. No curso de Antropologia tive oportunidade de fazer disciplinas como "Antropologia da Natureza" e "Antropologia da Saúde e da Doença" que contribuíram na minha reflexão. Senti necessidade de me aprofundar e me matriculei na disciplina "Saúde Indígena" ofertada no Instituto de Saúde Coletiva (ISCO), da UFOPA. Nessa ocasião, a partir de muita luta do movimento, iniciamos processo de inclusão dos povos indígenas do Baixo Tapajós como usuários da Secretaria Especial de Saúde Indígena (SESAI).

Em 2017, submeti outro projeto de pesquisa específico sobre saúde indígena "Os mestres dos saberes tradicionais: prevenção, tratamento e cura do povo Kumaruara" sob orientação do professor Hernane Guimarães. Ao mesmo tempo que essas experiências na universidade me proporcionaram acesso a uma visão diferente, fui provocada a escrever sobre como se dá o tratamento e cura dos indígenas entre meu povo. Resolvi, assim, centrar minha pesquisa nas práticas de cura do meu povo que são repassadas de geração para geração.

O fato de ter transitado em diversos espaços me proporcionou enxergar os modos de funcionamento do Estado que me possibilitou intervir na realidade. Hoje, percebo que o/a aluno/a contemplado/a com a reserva de vaga não deve apenas ocupar uma cadeira na sala de aula. $\mathrm{O}$ ingresso do indígena na universidade tem outras dimensões, uma delas é a demarcação territorial, pois este ou esta estudante tem um compromisso ainda maior dentro e fora dos muros da universidade. Pelo fato de eu ser jovem e mulher, encontrei muitas barreiras e vi o quanto é difícil transitar e se legitimar como liderança em espaços institucionais.

A partir de 2017 comecei a focar minha atuação no movimento indígena nas questões de mulheres, saúde e organização política do Território Kumaruara. Quando comecei a refletir sobre meu trabalho final de curso, tive a intenção de pesquisar o tema "Mulheres Indígenas". Em 2016, fui uma das facilitadoras de 
um diagnóstico da Organização das Nações Unidas (ONU) chamado "Voz das Mulheres Indígenas", durante o período das etapas local e regional, em Santarém, da Conferência Nacional de Políticas Indigenistas, e, assim, me despertou o interesse de atuar na pesquisa e na extensão com as mulheres. Essa oportunidade também apurou minha sensibilidade ao escutar suas experiências, ao escutar sobre diversas formas de violência que enfrentaram, dificuldades financeiras e de acesso à assistência médica, e os obstáculos em relação a participação política.

Tive contato com várias mulheres que ocupam cargos de prestígio dentro das aldeias, como São Pedro, Curucurui, Cabeceira do Amorim, Aningualzinho e outras, onde exercem papeis de cacicas, tuxaua, pajés, dentre outras funções como catequista e professoras. Infelizmente, não tive condições psicológicas para me debruçar e me aprofundar sobre esta temática. A professora Carla Ramos, da UFOPA, sempre me estimulou a pensar esta temática, mas tirou licença da universidade para cursar o doutorado e não me senti tão à vontade para dar continuidade.

De fato, se trata de um tema muito delicado, pois essas discussões ainda estão sendo amadurecidas e envolvem relações familiares e relações entre lideranças. Quando comecei a discutir publicamente sobre a violência contra as mulheres, machismo, e empoderamento das mulheres indígenas sofri retaliações. Sofri e sofro ainda consequências de ter impulsionado as discussões de gênero dentro do movimento indígena no Baixo Tapajós. São violências silenciosas que as pessoas não enxergam. Somente pessoas próximas a mim sabem o que enfrentei e estou enfrentando. Sofri ataques até mesmo em processo jurídico com o intuito de me criminalizar e deslegitimar minha atuação frente o movimento indígena. Não sucumbi. Em 2018, reativamos o Departamento de Mulheres do CITA e hoje há um grupo de mulheres indígenas que conduz esse debate e já se apropriou de informações e estratégias para ajudar as parentas. Seguimos em busca de nosso fortalecimento.

Minha militância na saúde indígena foi impulsionada, em 2015, quando houve um surto de hepatite na aldeia Solimões. Nós passamos muitas dificuldades pelo fato da Secretaria Especial de Saúde Indígena (SESAI), do Ministério da Saúde, se negar a nos assistir e nos reconhecer como sujeitos de direitos dessa política. Gestores federais alegavam que como não tínhamos terra demarcada, não tínhamos direito de ser atendidos. Então, fui estudar as políticas de saúde indígena. Fizemos denuncia no Ministério Público Federal, organizamos várias 
mobilizações, chamamos a imprensa e denunciamos a falta de assistência aos indígenas do Baixo Tapajós. Com muita luta, conseguimos acessar nossos direitos.

Até hoje atuo voluntariamente na saúde indígena indicada pelos/as parentes, desde 2017, para ser Presidente do Conselho Distrital de Saúde Indígena (CONDISI), representando os municípios de Santarém e Belterra no DSEI Guamá Tocantins. Participei em fórum do CONDISI em Belém e Conferências de Saúde Municipal e Conferência de Saúde Indígena, estive inclusive em Brasília pressionando com outros/as parentes três dos últimos ministros da Saúde. E assim vamos tentando manter o diálogo e efetivar as demandas. Uma delas, colocada nas últimas conferências de saúde indígena local e regional, é o reconhecimento de quem desenvolve a prática de cura e cuidado dentro das nossas aldeias, como pajés e parteiras, como profissionais de saúde. Em meio a todo esse envolvimento, é que resolvi dedicar meus estudos às questões da organização política das mulheres indígenas do Baixo Tapajós.

Em dezembro de 2018, na reta final do trabalho de conclusão do curso, fui apresentar trabalho na 31a RBA - Reunião Brasileira de Antropologia na Universidade de Brasília (UnB). Por várias situações que ocorreram e em meio aquele espaço do mundo intelectual, eu com uma visão critica do que acontecia ao meu redor, e que me incomodavam, senti a necessidade de dar mais um passo. É quando em conversa com antropólogas e também com minha atual orientadora Katiane Silva fui motivada e incentivada a fazer o processo seletivo do Programa de Pós-Graduação em Antropologia (PPGA) para Universidade Federal do Pará (UFPA), aonde hoje faço mestrado.

\section{Militância da mulher indígena e seu papel político no Baixo Tapajós}

A interpretação analítica sobre a militância da mulher indígena parte da minha vivência junto à história de vida de mulheres que atuavam ou atuam como lideranças. A abrangência dessa atuação é marcada pelo início da organização do departamento de mulheres indígenas na região do Baixo Tapajós, pelas trocas e contribuições com as diversas perspectivas sobre o movimento, contrapondo e/ou convergindo com o papel político (militância) das principais lideranças femininas que atuam na mobilização e no enfrentamento à violência e hoje em defesa da vida e dos territórios indígenas. 
Conhecer as experiências das mulheres indígenas no Baixo Rio Tapajós, permite traçar as dificuldades, interesses e as estratégias de luta das mulheres, protagonistas que se faz presente não só na "caminhada" junto ao coletivo indígena, mas também, refletem sobre a importância da mulher na tomada de decisão e de fazer valer a sua ótica no movimento indígena. Os discursos das mulheres indígenas apresentam convergências e divergências nos direcionamentos do movimento.

Contudo, é possível identificar situações em que a resistência das mulheres vem tomando espaço no campo dos cacicados, quando as mulheres têm assumido ou herdado o papel de cacicas, tuxauas e de pajés no contexto social e político específicos. Nesse sentido, as mulheres estão se reterritorializando politicamente nos espaços tidos antes como de dominação masculina. O papel político das muIheres indígenas configurou em um quadro de múltiplas identidades políticas, no qual as mulheres assumem posições em diferentes situações da vida cotidiana.

A realidade em que se encontra a mulher no movimento indígena do Baixo Tapajós contribuiu para a manutenção e valorização e permanência ou não no movimento, além de promover, indiretamente, o fortalecimento e aglutinação dos laços políticos entre os povos indígenas. Outros resultados importantes, também, puderam ser identificados como assimetria das características entre os dois perfis: universitárias (graduandas em Pedagogia, Antropologia, Direito, Farmácia e Gestão florestal), catequistas (religiosas que atuavam nas pastorais das CEB's), provenientes das mobilizações por reformas urbanas, inclusive com uma linguagem ambientalista, também proveniente de grêmios estudantis.

Em geral, o movimento foi constituído por mulheres solteiras e casadas e com e sem filhos/as. Sobre essa realidade constatou-se que apesar de terem sofrido com a forte pressão do sistema de "dominação masculina", as mulheres conseguiram estabelecer estratégias de resistência, delimitando o respeito às diferenças de gênero, sem cair no apelo do contra-discurso, que privilegia o biologismo e a fragilidade física, como forma de estabelecer padrões biologizados, usando a medição de força física ou formas desiguais de exercer o poder, tanto nas tomadas de decisão dos rumos do movimento indígena quanto sobre as reivindicações dos territórios indígenas. As mulheres indígenas por suas formas de organização têm sido aguerridas e bastante politizadas tanto nas formas de 
Memorial de uma liderança indígena: a construção política da trajetória...

driblando as armadilhas da colonização

reivindicar seu espaço no movimento; quanto na afirmação do seu papel como liderança nas aldeias.

O reflexo desta posição política feminina resulta na amplitude dos debates que vão além da questão da terra, mas do território que abarca necessidades centrais como a educação, saúde, meio ambiente e a empregabilidade por meio de projetos sociais e econômicos que valorizam a cultura e a identidade indígena nas suas aldeias.

\section{A territorialização política das mulheres indígenas do Baixo Tapajós}

Em 2017, nós, mulheres indígenas do Baixo Tapajós, por meio do nosso conselho representativo, Conselho Indígena Tapajós Arapiuns (CITA) organizamos três encontros regionais reunindo mulheres das nossas aldeias com a intenção de fortalecer nossa articulação dentro dos territórios. Realizamos os seguintes encontros regionais : I Encontro: Mulheres Indígenas da região do Rio Arapiuns, 20 e 21 de outubro de 2017, Aldeia São Pedro; II Encontro: Mulheres Indígenas do Planalto, Aveiro e Belterra, 04 e 05 de novembro de 2017, Aldeia Ipaupixuna; e o III Encontro: Mulheres Indígenas do Tapajós, 05, 06 e 07 de janeiro de 2018, Aldeia Solimões.

Nos encontros regionais mobilizamos cerca de 250 mulheres de todas as regiões do Baixo Tapajós. Hoje, de acordo com nosso Censo, somos 13 povos: Arapium, Apiaká, Arara Vermelha, Borari, Jaraqui, Kumaruara, Maytapu, Munduruku, Munduruku Cara- Preta, Tapajó, Tapuia, Tupayú e Tupinambá (Projeto Nova Cartografia Social, 2016), que vivem em 65 aldeias e também na cidade de Santarém. Estimamos nossa população em aproximadamente sete mil pessoas. Somos muitas e vivemos em uma grande extensão territorial, sendo que o acesso principal para nossas aldeias é feita pelos rios. Isso traz desafios para a nossa organização política, pois demanda tempo e dinheiro para conseguir reunir as participantes dos eventos. Para compartilhar informações usamos de diferentes estratégias como envio de documentos por intermédio dos barcos e enviando recado por parentes que se deslocam pelos rios. Mas, nem sempre funciona com rapidez e eficiência exigidas pelo movimento.

Uma das questões que definimos como prioritária nos encontros regionais foi viabilizar a eleição do Departamento de Mulheres do CITA para poder voltar 
a nos articular dentro do nosso conselho. Desse modo, após a renovação da coordenação do nosso conselho, o CITA, que aconteceu efetivamente em junho de 2018, iniciamos articulação para composição do departamento de mulheres. Então, nós decidimos realizar uma assembleia das mulheres com objetivo principal de eleger aquelas que ficarão à frente do departamento de mulheres.

Figura 4 - Encontro de Mulheres Indígenas na aldeia de Solimões (janeiro/2018)

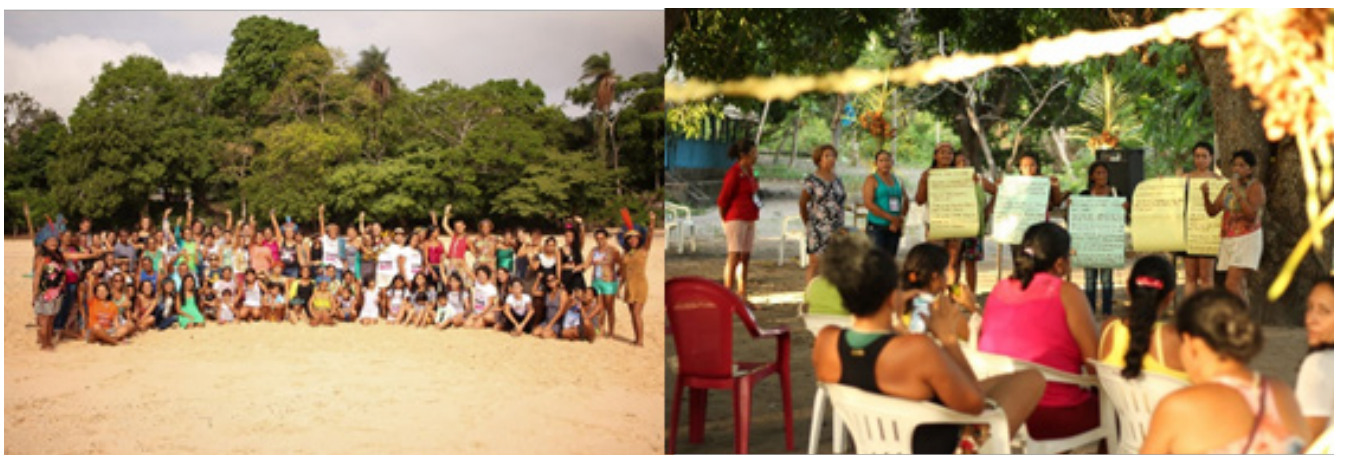

Foto: Vanessa Barros

Realizamos a Assembleia de Mulheres, entre os dias 3 e 5 de setembro de 2018, na região Planalto Santareno para dar visibilidade a nossa luta. Os povos Munduruku e Apiaká do Planalto não têm garantido o direito ao território tradicionalmente ocupado. Além da terra indígena não estar demarcada, os parentes sofrem pressão cotidiana do avanço da monocultura da soja na região. As lideranças vivem sob ameaça dos "sojeiros", a terra está envenenada por agrotóxico, os igarapés morreram, grande proporções do território foi desmatada. A situação é alarmante, a violência e a insegurança se faz presente razão pela qual decidimos realizar nossa assembleia na aldeia Açaizal, no Planalto.

Nos nossos encontros dialogamos sobre diversos assuntos, os quais dizem respeito a nossa cultura, a luta pelo acesso e gestão de nossos territórios e ao nosso bem viver. Discute-se sobre acesso às políticas públicas de saúde, educação e demarcação de terras. Conversa-se muito a respeito dos desafios de ser mulher e participar das atividades do movimento indígena, pois temos tarefas domésticas que dificultam nossa saída, uma vez que os cuidados com filhos, casa, alimentação, roça ficam sob nossa responsabilidade. Além disso, é comum nossos maridos 
Memorial de uma liderança indígena: a construção política da trajetória...

driblando as armadilhas da colonização

tentarem e mesmo impedirem nossa participação. Criamos espaços de acolhimento para as mulheres indígenas compartilharem seus sofrimentos, para nos apoiar e construir estratégias para superar todos os tipos de violências que vivenciamos.

Para nós, mulheres indígenas, é muito importante quando estamos juntas termos tempo para nossas atividades manuais. Por isso, gostamos de realizar oficinas de remédio caseiro, material limpeza, artesanato, corte e costura, entre outras. É um momento de troca de conhecimento, produção de materiais para nosso consumo e, também, para comercialização, fala-se de política, coloca-se a conversa em dia, e fortalecemos nossos laços de amizade e afeto.

Esse processo de proporcionar encontros entre nós nos fortalece e nos motiva a lutar pelos direitos dos nossos povos e pelo nosso território. Cada dia mais mulheres indígenas se juntam a nossa luta! É esse o caminho que estamos construindo! As guerreiras indígenas do Baixo Tapajós fortes e unidas na resistência em defesa da nossa existência.

\section{REFERÊNCIAS}

HARRIS, Mark. Rebellion on the Amazon: the Cabanagem, race, and popular culture in the North of Brazil, (1798-1840). Cambridge: University Press, 2010.

PROJETO NOVA CARTOGRAFIA. Caderno nova cartografia social: resistência e mobilização dos povos indígenas do baixo tapajós. Manaus: UEA Edições, 2016.

VAZ FILHO, Florêncio Almeida. Pajés, benzedores, puxadores e parteiras: os imprescindíveis sacerdotes do povo na Amazônia. Santarém: UFOPA, 2016. 138 p.

VAZ FILHO, Florêncio Almeida; CARVALHO, Luciana Goncalves de. Isso tudo é encantado. Santarém: UFOPA, 2013. 126 p.

\section{Sobre a autora:}

Luana da Silva Cardoso-Mestranda no Programa de Pós-graduação em Antropologia (PPGA) na Universidade Federal do Pará. E-mail: luanadasilva.stm@gmail.com

Recebido em 20 de setembro de 2018

Aceito em 09 de maio de 2019 
